\title{
Relationship between adiposity and heart rate recovery following an exercise stress test in obese older women
}

\section{Relação entre a adiposidade $e$ a recuperação da frequência cardíaca após teste de esforço em mulheres idosas obesas}

\author{
Cristiane Rocha da Silva \\ Bruno Saraiva \\ Dahan Cunha Nascimento $0^{1,2}$ \\ Luana Claudia Dias Bicalho² \\ Ramires Alsamir Tibana ${ }^{3}$ \\ Jeffrey M. Willardson ${ }^{4}$ \\ Jonato Prestes \\ Guilherme Borges Pereira
}

Abstract - The aim of the present study was to compare differences in heart rate (HR) response during and following exercise in obese older women with different percent body fat levels. Ninety older, obese women aged 60-87 years participated in the study, were categorized, and enrolled to one of two groups based on a lower percent body fat (LPBF $\leq 41.10 \%)$ or higher percent body fat (HPBF > $41.10 \%)$ as measured by dual-energy $\mathrm{x}$-ray absorptiometry. The peak HR during exercise and in the first and second minutes of recovery period were compared between groups. The HPBF group presented a lower peak HR during exercise $(p=.001)$ and an impaired HR recovery $(p=.001)$ when compared to LPBF group. The present study demonstrated that older women who were in exceedingly obese level have an impaired heart rate response during exercise and in the recovery period, indicating possible autonomic dysfunction.

Key words: Aging; Obesity; Heart rate.

Resumo - O objetivo do presente estudo foi comparar a reposta da frequência cardiaca (FC) durante e após um teste de esforço entre mulheres idosas obesas com diferentes niveis de percentual de gordura corporal. Noventa idosas obesas com idade entre 60-87 anos participaram desse estudo e foram separadas em dois grupos com base no baixo percentual ( $L P B F \leq 41.10 \%$ ) e alto percentual de gordura corporal (HPBF $>41.10 \%)$ medido por absorciometria de raio- $x$ de dupla energia. A FC pico durante o teste e no primeiro e segundo minuto de recuperação foram comparadas entre os grupos. O grupo HPBF apresentou FC pico inferior durante o teste $(p=0.001)$ e também após o periodo de recuperação $(p=0.001)$ quando comparado com o grupo LPBF. Os dados desse estudo demonstraram que mulheres idosas com alto percentual de gordura corporal apresentaram $F C$ pico inferior e menor recuperação da $F C$ durante o periodo de recuperação, indicando possivelmente uma disfunção autonômica.

Palavras-chave: Envelhecimento; Frequência cardiaca; Obesidade.
1 Universidade Católica de Brasília. Programa de Pós-Graduação em Educação Física. Brasília, DF. Brasil.

2 Centro Universitário do Distrito Federal. Brasília, DF. Brasil.

3 Universidade Federal do Mato Grosso. Departamento de Educação Física. Cuiabá, MT. Brasil.

4 Rocky Mountain College. Billings, MT. USA.

Received: 20 March 2017 Accepted: 12 October 2017

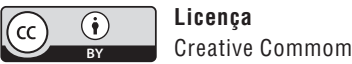




\section{INTRODUCTION}

Recent research demonstrated an increase in the prevalence of individuals classified as overweight or obese among the Brazilian population ${ }^{1}$. Obesity is a medical condition characterized by excessive accumulation of body fat, capable of triggering unfavourable changes in the heart and vascular system and causing autonomic nervous system dysfunction ${ }^{2}$.

The physiological variable, heart rate recovery (HRR), is an important, non-invasive measure utilized after a stress test that provides useful information about vagal control of the autonomic nervous system and cardiovascular fitness ${ }^{3,4}$. A slower HRR has been associated with decreased parasympathetic activity and reduced cardiovascular fitness ${ }^{5}$. Furthermore, previous studies demonstrated a negative correlation between HRR and mortality in healthy participants ${ }^{6}$ and individuals with high relative risk of acute myocardial infarction ${ }^{7}$.

The increase in percentage body fat is also associated with autonomic nervous system dysfunction of the cardiovascular system ${ }^{8}$. In obese subjects, this impairment is reflected by reduced parasympathetic nervous system function and/or sympathetic nervous system overactivity ${ }^{9}$. Furthermore, a study in obese subjects with low levels of physical fitness revealed an impaired chronotropic index and HRR during and after exercise stress testing ${ }^{10}$.

Several studies have shown that parameters of obesity negatively affect HRR following exercise ${ }^{11-13}$. Barbosa et al. ${ }^{13}$ analysed the relationship between body mass index (BMI) and HRR after one minute of exercise and demonstrated that obese subjects $\left(>30 \mathrm{~kg} / \mathrm{m}^{2}\right)$ presented higher basal HR and lower maximum HR accompanied by reduced chronotropic reserve. Deniz et al. ${ }^{14}$ reported that HRR was impaired in young adult males with metabolic syndrome as compared with obese subjects without metabolic syndrome. In addition, Gondoni et al. ${ }^{15}$, demonstrated severely obese subjects (BMI > 40 $\mathrm{kg} / \mathrm{m}^{2}$ ) exhibited lower HRR and a lower peak HR when compared with subjects with normal BMI $\left(<25 \mathrm{~kg} / \mathrm{m}^{2}\right)$, and the blunted increase in HR was the most important factor that influenced exercise capacity ${ }^{15}$.

Although BMI is an acceptable index in younger adults, errors occur when assessing older adults, thereby limiting its use in this population. Thus, the dual-energy x-ray absorptiometry (DEXA) method was chosen because it allows a non-invasive measurement of body adiposity while adjusting for changes in lean body mass and better comprehension of obesity measurement classification in the older adult population ${ }^{16}$.

To date, HRR has not been directly investigated as a non-invasive correlative tool to detect cardiovascular health with older women classified on different levels of adiposity by DEXA. This information would be valuable for the identification and monitoring of older adults with high cardiovascular risk pre- and post-exercise training. Thus, the aim of the present study was to compare differences in HR response during and following exercise in older women who were categorized into different groups based on body fat percentage as determined by DEXA. The hypothesis of this study was 
that older women classified as higher percent body fat (HPBF) would have a lower peak HR during exercise and an impaired HRR following exercise versus older women with a lower percent body fat (LPBF).

\section{METHODOLOGICAL PROCEDURES}

\section{Participants}

A convenience sampling of community-dwelling older $(n=157)$ women from the Centro de Convivência do Idoso located at Catholic University of Brasilia were recruited for participation in the present study. The present study was approved by the Institutional Research Ethic Committee of Catholic University of Brasília (protocol 45648115.8.0000.5650/2016). To be elegible for participation in this study, women needed to be aged $60-100$ years with body fat percentages $\geq 30 \%$ as assessed by DEXA. Of those, 67 were excluded (did not meet inclusion criteria) leaving a total of 90 participants who met the inclusion criteria.

During the first visit, participants were interviewed and responded anamnesis given by the researcher. During the second visit, participants answered a questionnarie to obtain lifestyle information, use of medications, and leisure type physical activity (LTPA) ${ }^{17}$. After that, participants were submitted to a body composition assessment and exercise treadmill testing.

Participants were divided into two groups: LPBF $(\leq 41.10 \%=50$ th percentile) and HPBF (> $41.10 \%$ ). In addition, the cut-off values were close to obese classifications using percent body fat (DEXA exam) as recommended by Gallagher et al. ${ }^{18}$ for African American (41 \%) and Asian (41 \%) adults. The characteristics of the study participants are presented in Table 2. Obesity was considering a cut-off point of $30 \%$ for women ${ }^{19}$.

\section{Leisure type physical activity (LTPA)}

The LTPA was evaluated based in a previous publication ${ }^{17}$. Subjects were asked to classify the types, frequency, and duration of weekly LTPA completed by them during the previous month. On the basis of Ainsworth ${ }^{20}$, compedium of physical activities were defined using a metabolic equivalent value (MET; $1 \mathrm{MET}=1 \mathrm{kcal}$ per $\mathrm{h} / \mathrm{kg}$ of bodyweight) of $3.5 \mathrm{METs}$ for a conditioning exercise, 3.0 METs for resistance training exercise (Cod 02130), 3.0 METs for walking exercise (Cod 17200), 4.0 METs for water activities (Cod 18355), 5.0 METs for dancing (Cod 03020) and 2.5 METs for stretching (Cod 02100) were used. The subjects indicating activities in more than one intensity category, a weighted MET value was applied, considering the length of time engaged in each category. Considering LTPA volume as being the product of intensity (MET) and the duration of exercise (h), the MET-h per week of each participant was calculated.

\section{Anthropometrics and body composition}

Anthropometric status was evaluated by the following measures: height (to the nearest $0.1 \mathrm{~cm}$ ) and body weight (to the nearest $0.1 \mathrm{~kg}$ ), and these 
were used to calculate BMI (body weight/height ${ }^{2}$ ).

Percent body fat and fat-free mass were determined via DEXA (General Electric-GE model 8548 BX1L, year 2005, Lunar DPX type, Software Encore 2005; Rommelsdorf, Germany). The tests included a complete body scan of the volunteers, in the supine position, with the apparatus calibrated and operated by a technically trained professional. The legs were secured by nonelastic straps at the knees and ankles, and the arms were aligned along the trunk with the palms facing the thighs. The coefficient of variation for the percent body fat estimated by DEXA was 8.74 and $15.92 \%$ for the LPBF and HPBF groups, respectively. All metal objects were removed from the participant before the scan.

\section{Treadmill stress testing}

Exercise testing procedures in the laboratory have been described in detail elsewhere ${ }^{1321}$. Participants underwent a symptom-limited treadmill test using a ramped protocol. The protocol used velocity initial and final velocity was $3.0 \mathrm{~km} / \mathrm{h}$ and $6.0 \mathrm{~km} / \mathrm{h}$, while the initial and final grade was 1.0 and $14.0 \%$, respectively and maximal exercise capacity within the recommended range of 8 to 12 minutes. Participants were encouraged to exercise until volitional-exhaustion. Achievement of $85 \%$ of age-predicted maximum HR and/or respiratory exchange ratio $>1.02$ were used for testing termination ${ }^{21}$. During each exercise stage and recovery stage, symptoms (chest discomfort, rate of perceived exertion, and dizziness), blood pressure, and HR were recorded. Following peak exercise (maximum time spent in the test), participants walked for a 2-minute cool-down period at $2.0 \mathrm{~km} / \mathrm{h}$ and $2.5 \%$ grade $^{22}$. Heart rate recovery was measured during the 2-minute cool-down period and relative HRR indices were defined as the absolute differences between peak HR and the HR values measured at $60 \mathrm{~s}$ (HRR60s) and $120 \mathrm{~s}$ (HRR120s) of recovery. For safety purposes, participants were permitted to lean on handrails during exercise.

Chronotropic incompetence was assessed as failure to achieve $85 \%$ of the age-predicted HR. A chronotropic index less than 0.80 was also considered by the following equation [(HRstage - HRrest $) /(220$ - age in years - HRrest)] x 100 (Lauer et al.) ${ }^{23}$. Maximal metabolic equivalent (MET) level was calculated for each participant using the following equation: maximal MET level $=($ treadmill time in minutes X 1.750 $)+10.5 / 3.5$ (Farrel et al.) ${ }^{24}$. Maximal metabolic equivalent was calculated because it represents a standard scale for expressing workload and is related with all-cause mortality, coronary heart diseases, cardiovascular disease events, and heart-rate recovery ${ }^{22,25}$.

\section{Statistical analyses}

All statistical analyses were conducted using SPSS software version 18.0 (Chicago, USA). Normality was verified by Shapiro-Wilk test. Independent $t$ tests were used for comparisons between groups. For non-parametric variables (disease, medications, chronotropic incompetence, and chrono- 
tropic index), a Chi square for proportions was used and Cramer's $V$ test of association was applied. First, the multiple linear regression utilized the forward step elimination method for independent variables in the model (percent body fat, BMI, MET, WC, WHR, hypertension, diabetes, and age], according to recommendations from literature ${ }^{13,12,22}$.The continuous dependent variable (1 minute HR recovery) was chosen based on previous research ${ }^{22}$. It is noteworthy that the time constant of an earlier phase of the heart rate (e.g. 30 seconds and 1 minute) decay might predominantly reflect the rapid vagal reactivation ${ }^{26}$. In the final model, the significant variables were: percentage body fat, MET, and age. Secondly, a hierarchical multiple regression with interactions between age and MET, age and percentage body fat, and MET and percentage body fat was also applied. Third, to determine whether the multiple regression model is a good fit for the data. The $\mathrm{R}^{2}$ for the overall model was $25.5 \%$ with an adjusted $\mathrm{R}^{2}$ of $20.1 \%$, and a medium effect size. In addition, all variables added statistically significantly to the model, $\mathrm{F}(6,83)=(4.72), \mathrm{p}=0.001$. Linearity was confirmed by partial regression plots and a plot of studentized residuals against the predicted values. Independence of residuals was verified, as assessed by a Durbin-Watson statistic of 2.101. Homoscedasticity was confirmed, as assessed by visual inspection of a plot of studentized residuals versus unstandardized predicted values, and no evidence of multicollinearity was present, as assessed by tolerance values greater than 0.1.). An a priori power analysis for independent $t$-test, based on our pilot study $(n=53)$, was used to determine the necessary sample size to have statistical power at $80 \%{ }^{27}$. The sample power was calculated by the software $G^{*}$ Power 3.1.6, and determined that the study would be adequately powered with a 0.75 effect size at 45 subjects per group. An alpha level of $p<.05$ was considered significant.

\section{RESULTS}

No differences between groups for hypertension and diabetes $\left(X^{2}(1)=\right.$ 1.21 , Cramer's $V=0.11$ ) was observed. In addition, no difference between groups in the use of diuretics $\left(X^{2}(1)=0.18\right.$, Cramer's $\left.V=0.18\right), \beta$-blockers $\left(X^{2}(1)=0.72\right.$, Cramer's $\left.V=0.08\right)$, calcium channel antagonists $\left(X^{2}(1)=\right.$ 0.45 , Cramer's $V=0.07)$, angiotensin converting enzyme inhibiters $\left(X^{2}(1)\right.$ $=0.30$, Cramer's $V=0.05)$, and hypoglycemic medications $\left(X^{2}(1)=1.21\right.$, Cramer's $V=0.11$ ) was verified. The LPBF group presented a higher frequency for statins use $\left(X^{2}(1)=4.48\right.$, Cramer's $\left.V=0.22\right)$. In addition, HPBF demonstrated a higher frequency of chronotropic incompetence $\left(X^{2}(1)=3.98\right.$, Cramer's $\left.V=0.21\right)$ and chronotropic index $\left(X^{2}(1)=8.36\right.$, Cramer's $V=0.30$ ) than LPBF group (Table 1 ).

The HPBF group presented a lower treadmill exercise time ( $p=.019)$, peak $\mathrm{O}_{2}$ consumption $(p=.001)$, chronotropic index $(p=.001)$, peak heart $(p=.001), 1$-minute relative $\operatorname{HRR}(p=.001)$, and 2-minutes relative HRR $(p=.015)$ versus the LPBF group. Furthermore, body weight $(p=.001)$, 
$\operatorname{BMI}(p=.001)$, and percent body fat $(p=.001)$ were higher in the HPBF group versus the LPBF group (Table 2).

Table 1. Diseases, medications and chronotropic incompetence characteristics of the subjects.

\begin{tabular}{|c|c|c|c|c|c|}
\hline & $\begin{array}{l}\text { LPBF } \\
(n=45)\end{array}$ & & $\begin{array}{l}\text { HPBF } \\
(n=45)\end{array}$ & & $X^{2}$ \\
\hline Disease & Yes & No & Yes & No & \\
\hline Essential hypertension & $32(71.1)$ & $13(28.9)$ & $34(75.6)$ & $11(24.4)$ & 0.634 \\
\hline Diabetes mellitus type 2 & $16(35.6)$ & $29(64.4)$ & $22(48.9)$ & $23(51.1)$ & 0.270 \\
\hline \multicolumn{6}{|l|}{ Medications } \\
\hline Angiotensin receptor blockers & $16(35.6)$ & $29(64.4)$ & $22(48.9)$ & $23(51.1)$ & 0.200 \\
\hline Diuretics & $20(44.4)$ & $25(55.6)$ & $18(40.0)$ & $27(60.0)$ & 0.670 \\
\hline$\beta$-blockers & $6(13.3)$ & $39(86.7)$ & $9(20.0)$ & $36(80.0)$ & 0.396 \\
\hline Calcium channel antagonists & $6(13.3)$ & $39(86.7)$ & $4(8.9)$ & $41(91.1)$ & 0.502 \\
\hline $\begin{array}{l}\text { Angiotensin-converting enzyme } \\
\text { inhibiters }\end{array}$ & $9(20.0)$ & $36(80.0)$ & $7(15.6)$ & $38(84.4)$ & 0.581 \\
\hline Statins & $17(37.8)$ & $28(62.2)$ & $8(17.8)$ & $37(82.2)$ & $0.034^{*}$ \\
\hline Hypoglycemic Medications & $10(22.2)$ & $35(77.8)$ & $6(13.3)$ & $39(86.7)$ & 0.270 \\
\hline \multicolumn{6}{|l|}{ Chronotropic evaluation } \\
\hline Chronotropic incompetence & $11(24.4)$ & $34(75.6)$ & $20(44.4)$ & $25(55.6)$ & $0.046^{*}$ \\
\hline Chronotropic index & $9(20.0)$ & $36(80.0)$ & $22(48.9)$ & $23(51.1)$ & $0.004^{*}$ \\
\hline
\end{tabular}

Values are expressed as frequencies and percentage. ${ }^{*}$ Statistically significant, $X^{2}=$ qui-square.

Table 2. Characteristics of the subjects.

\begin{tabular}{|c|c|c|c|}
\hline Anthropometrics & $\operatorname{LPBF}(n=45)$ & $\operatorname{HPBF}(n=45)$ & $\mathrm{P}$ \\
\hline & Mean (S.D.) & Mean (S.D.) & \\
\hline Age, years & $69.67 \pm 6.11(67.83-71.50)$ & $66.60 \pm 5.58(64.92-68.28)^{*}$ & 0.015 \\
\hline Height, m & $1.54 \pm 0.05(1.52-1.55)$ & $1.54 \pm 0.07(1.51-1.56)$ & 0.851 \\
\hline $\mathrm{BMI}, \mathrm{kg} / \mathrm{m}^{2}$ & $26.12 \pm 3.18(25.16-27.08)$ & $31.53 \pm 3.72(30.42-32.65)^{*}$ & 0.001 \\
\hline Body fat, \% & $34.73 \pm 3.97(33.54-35.93)$ & $44.92 \pm 2.82(44.07-45.76)^{*}$ & 0.001 \\
\hline \multicolumn{4}{|l|}{ Functional Capacity } \\
\hline $\mathrm{MET} / \mathrm{h}$ per week & $8.89 \pm 6.38(6.98-10.81)$ & $8.90 \pm 6.75(6.87-10.93)$ & 0.995 \\
\hline \multicolumn{4}{|l|}{ Exercise test variables } \\
\hline Treadmill exercise time, minute & $8.05 \pm 2.15(7.40-8.69)$ & $7.03 \pm 1.85(6.47-7.59)^{\star}$ & 0.019 \\
\hline Peak $\mathrm{O}_{2}$ consumption, $\mathrm{ml} / \mathrm{kg}$ & $19.39 \pm 2.71(18.55-20.23)$ & $17.07 \pm 2.92(16.19-17.96)^{\star}$ & 0.001 \\
\hline Chronotropic index & $0.97 \pm 0.21(0.90-1.03)$ & $0.84 \pm 0.20(0.78-0.90)^{\star}$ & 0.005 \\
\hline Systolic blood pressure, mmHg & $127.03 \pm 18.13(121.58-132.48)$ & $125.58 \pm 11.65(122.08-129.08)$ & 0.652 \\
\hline Diastolic blood pressure, $\mathrm{mmHg}$ & $73.25 \pm 9.58(70.37-76.13)$ & $72.73 \pm 9.03(69.76-74.56)$ & 0.557 \\
\hline Basal heart rate, bpm & $75.42 \pm 11.78(71.88-78.96)$ & $72.73 \pm 9.03(70.01-75.44)$ & 0.228 \\
\hline Peak heart rate, bpm & $146.36 \pm 14.91(141.87-150.84)$ & $139.09 \pm 18.05(133.66-144.51)^{*}$ & 0.040 \\
\hline 1 minute relative HRR, bpm & $25.24 \pm 10.31(22.15-28.34)$ & $18.84 \pm 7.70(16.53-21.16)^{\star}$ & 0.001 \\
\hline 2 minute relative $H R R, b p m$ & $35.71 \pm 11.80(32.03-39.39)$ & $29.62 \pm 9.73(26.38-32.87)^{*}$ & 0.015 \\
\hline MET & $17.09 \pm 3.76(15.96-18.22)$ & $15.31 \pm 3.25(14.33-16.29)^{*}$ & 0.019 \\
\hline
\end{tabular}

$\mathrm{BMI}=$ body mass index, $\mathrm{LBF}=$ low body fat percentage, $\mathrm{HBF}=$ high body fat percentage, $\mathrm{V} 02$ = volume of oxygen consumed, ${ }^{*} \mathrm{P}<0.05$ low body fat group vs. high body fat group.

The addition of percent body fat (Model 1) led to statistically significant increase in $R^{2}$ of $0.10, F(1,88)=10.38, p=.002$. Moreover, the addition of 
the MET value (Model 2) was statistically significant $\left(R^{2}\right.$ of $0.18, F(1,87)$ $=8.57, p=.004)$. Also, the addition of age (Model 3) was statistically significant $\left(R^{2}\right.$ of $\left.0.23, F(1,86)=5.90, p=.017\right)$. For the model parameters (Model 3), percentage body fat, MET, and age were statistically significant. This value indicates that as aging increases by one unit, HRR decreases by 0.39 units. As percentage body fat increases by one unit, HRR decreases by 0.50 units. However, as MET increases by one unit, HRR increases by 0.61 units. This interpretation is true only if the effects of variables introduced in the multiple regression are held constant. The addition of interaction between age and $\operatorname{MET}\left(R^{2}\right.$ of $\left.0.23, F(1,85)=0.04, p=.826\right)$, interaction between age and percent body fat $\left(R^{2}\right.$ of $0.25, F(1,84)=1.33$, $p=.252)$, and interaction between MET and percent body fat $\left(R^{2}\right.$ of 0.25 , $F(1,83)=0.45, p=.502)$ did not lead to a statistically significant increase in $R^{2}$ (data not shown) (Table 3 )

Table 3. Hierarchical multiple regression predicting 1 minute HRR from percent body fat, BMI, and age.

\begin{tabular}{|c|c|c|c|c|c|c|c|c|c|}
\hline \multirow[b]{3}{*}{ Variable } & & \multicolumn{8}{|c|}{1 minute HRR } \\
\hline & \multicolumn{3}{|c|}{ Model 1} & \multicolumn{3}{|c|}{ Model 2} & \multicolumn{3}{|c|}{ Model 3} \\
\hline & $\mathrm{B} \ddagger$ & $\mathrm{B} \dagger$ & $95 \% \mathrm{Cl}$ for $\mathrm{B}$ & $\mathrm{B} \ddagger$ & $\mathrm{B} \dagger$ & $95 \% \mathrm{Cl}$ for $\mathrm{B}$ & $B \ddagger$ & $\mathrm{B} \dagger$ & $95 \% \mathrm{Cl}$ for $\mathrm{B}$ \\
\hline Constant & $42.21^{*}$ & & & $24.37^{\star}$ & & & $58.73^{*}$ & & \\
\hline Percent body fat & $-0.50^{*}$ & -0.32 & $-0.81--0.19$ & $-0.37^{\star}$ & -0.24 & $-0.69--0.06$ & $-0.50^{*}$ & -0.32 & $-0.82--0.18$ \\
\hline MET & & & & $0.78^{\star}$ & 0.29 & $2.52-1.31$ & $0.61^{*}$ & 0.23 & $0.07-1.15$ \\
\hline Age & & & & & & & $-0.39^{*}$ & -0.24 & $-0.71--0.07$ \\
\hline $\mathrm{R}^{2}$ & $0.10^{*}$ & & & $0.18^{*}$ & & & $0.23^{*}$ & & \\
\hline $\mathrm{F}$ & $10.38^{*}$ & & & $9.92^{*}$ & & & $8.96^{\star}$ & & \\
\hline$\Delta \mathrm{R}^{2}$ & 0.10 & & & 0.08 & & & 0.05 & & \\
\hline$\Delta \mathrm{F}$ & 10.38 & & & 8.57 & & & 5.90 & & \\
\hline
\end{tabular}

$N=88 .{ }^{*} P<0.05, \ddagger=$ unstandardized beta, $\dagger=$ standardized beta, $\mathrm{HHR}=$ heart rate recovery.

\section{DISCUSSION}

The main findings from our analyses confirmed the hypothesis that older adults who were classified in the HPBF group demonstrated a lower peak HR during an exercise stress test and an impaired HRR 1-minute and 2-minutes after exercise.

During aging the cardiovascular system deteriorates as indicated by a reduced maximal $\mathrm{HR}$, ejection fraction, and maximal cardiac output during exercise $^{28}$. Reductions in $\beta$-adrenergic stimulated chronotropic response largely explain the decrease in maximal HR with aging ${ }^{28}$ and contribute to an attenuated left ventricular contractile response to exercise ${ }^{28,29}$. Moreover, a lower synaptic concentration of norepinephrine, diminished levels of circulating epinephrine, and impaired beta-adrenergic receptor or post-receptor responsiveness might also explain an impaired HR response to exercise, as seen in the current study wherein the HPBF group had inferior treadmill exercise time versus the LPBF group ${ }^{2129}$. Although with aging, heart rate is more accelerated after exercise due to the slow 
withdrawal of norepinephrine in the bloodstream, there is evidence that, shortly after physical exercise, vagal modulation is primarily responsible for the drop in HR, especially in the first 30 seconds after exercise ${ }^{26}$.

In obese subjects, the activity of renin-angiotensin complex and sympathetic nervous systems are also increased during a standardized treadmill protocol when compared to lean subjects, despite hypertension status ${ }^{3}$. This evidence may support the theory that a high percentage body fat might potentiate abnormal chronotropic response and lower peak HR in the group with more adiposity by the attenuated neurohormonal response to exercise. Thus, this different neurohormonal response might help to explain the disparity in their cardiovascular response (e.g. inferior chronotropic index and higher percentage chronotropic incompetence) between HPBF and LPBF subjects.

Regarding the impaired HRR after exercise, it could be inferred that the HPBF group experienced delayed sympathetic nervous system withdrawal compared with the LPFB group. In addition, a later stage parasympathetic reactivation might be prolonged in the HPBF group, which contributed to impaired HRR following 1-minute and 2-minutes after the treadmill exercise stress test. Although reasonable, these autonomic responses to exercise are only speculated because these measurements were not assessed in the present study.

Another hypothesis for the differences between groups is the existence of a work load dependence of heart rate decay. Heart rate at the end of the exercise is increased with increasing work load ${ }^{26}$. As we know, chemosensitive muscle afferents in exercising legs are important in the regulation of autonomic nerve activities during exercise. Thus, after cessation of exercise, metabolites might persist stimulating the muscle afferents in exercising legs and attenuate vagal reactivation ${ }^{26}$, while this must be confirmed in future studies.

Moreover, all-cause mortality is likely to be affected by this higher proportion of chronotropic incompetence, chronotropic index, and attenuated exercise HR response in the HPBF group. In addition, Lauer et al. ${ }^{23}$ demonstrated that subjects who failed to reach $85 \%$ of their age-predicted maximum HR and who had a low chronotropic index had higher death rates ${ }^{23}$.

In this study, after adjusting for covariates using hierarchical multiple regression percentage body fat, $\mathrm{MET}$, and age were negative determinants of 1-minute HRR. The results are in line with three previous studies ${ }^{10,13}$, that a higher percentage body fat and age were associated with an impaired HRR. Moreover, a higher maximal MET level was associated with a better HRR following 1-minute post treadmill exercise testing. Thus, a better cardiorespiratory fitness is associated with a lower risk of all-cause mortality, reduced risk for coronary heart disease, and all-cause mortality in women than $\mathrm{BMI}^{30}$.

For the cardiorespiratory fitness (METs) calculated for treadmill exercise, it was verified that the HPBF group presented lower performance than the LPBF group. Furthermore, it is important to mention that better cardiorespiratory fitness is associated with a lower risk of all-cause mortal- 
ity, reduced risk for coronary heart disease, and is a stronger risk factor of all-cause mortality in women ${ }^{30}$.

The present study had some limitations that should be considered, such as the lack of a direct measure of autonomic tone and heart rate variability. Thus, the hypothesis that an autonomic imbalance is the main determinant of $\mathrm{HR}$ behaviour warrants further investigation. Moreover, the convenience sampling used in this study indicates that subjects from this study were not specifically representative of the Brazilian population, as they were recruited on a voluntary basis from the local community.

It is relevant to mention that, although no differences between groups were found for the use of medications, the sample used in this study do not offer enough statistical power to detect these differences. Some medications, such as nondihydropyridine calciun-channel, and beta blockers might blunt heart rate recovery following exercise ${ }^{22}$.

\section{CONCLUSION}

In conclusion, older women classified with higher percentage body fat presented a lower chronotropic index, lower peak HR, and an impaired HRR after exercise. Overall, these findings emphasize that body fat may be used to specify exercise prescription for older women who are also obese. On the other hand, HRR active or passive is closely linked to vagal tone modulation. As mentioned, the parasympathetic activity is considered as a cardiovascular protection factor and a dysfunction in the cardiac vagal tone, therefore, increases the risk of cardiovascular death ${ }^{26}$. Thus, the RFC is a very important measure that should have special attention and can be part of the clinical and / or physical evaluation of subjects, such as the obese elderly population. Although the percentage body fat evaluated by DEXA does not represent a practical tool for the assessment of an impaired HRR after exercise in routine clinical practice. We encourage researchers to verify another simple and low cost variable for the same goal.

\section{Acknowledgements}

The authors have no conflicts of interest that are directly relevant to the content of this manuscript. The authors thank the laboratory LAFIT (Daniele Garcia and contributors). The authors also acknowledge the financial support from Coordenação de Aperfeiçoamento de Pessoal de Nível Superior (CAPES) and Fundação de Apoio a Pesquisa do Distrito Federal (FAP/ DF). Authors would like to advise that all authors listed have contributed to the work and approved the content of the submitted manuscript.

\section{REFERENCES}

1. Vigilância de Fatores de Risco e Proteção para Doenças Crônicas por Inquérito Telefônico.2014; Available from: <http://bvsmssaudegovbr/bvs/publicacoes/vigitel_brasil > [2016 Jul. 12].

2. Lopes HF, Egan BM. Autonomic dysregulation and the metabolic syndrome: pathologic partners in an emerging global pandemic. Arq Bras Cardiol 2006; (87): 538-47. 
3. Weber MA, Neutel JM, Smith DH. Contrasting clinical properties and exercise responses in obese and lean hypertensive patients. J Am Coll Cardiol 2001; (37):169-74.

4. Brinkworth, Grant D, Noakes, M Buckley, J D Clifton, PM. Weight loss improves heart rate recovery in overweight and obese men with features of the metabolic syndrome. Am Heart J 2006; 152 (4):693-e1.

5. Cole CR, Foody JM, Blackstone EH, Lauer MS. Heart rate recovery after submaximal exercise testing as a predictor of mortality in a cardiovascularly healthy cohort. Ann Intern Med 2000; (132): 552-5.

6. Nishime EO, Cole CR, Blackstone EH, Pashkow FJ, Lauer MS. Heart rate recovery and treadmill exercise score as predictors of mortality in patients referred for exercise ECG. JAMA 2000; (20): 1392-8.

7. 7.Kligfield P, McCormick A, Chai A, Jacobson A, Feuerstadt P, Hao SC. Effect of age and gender on heart rate recovery after submaximal exercise during cardiac rehabilitation in patients with angina pectoris, recent acute myocardial infarction, or coronary bypass surgery. Am J Cardiol 2003; (1): 600-3

8. Castner DM, Rubin DA, Judelson DA, Haqq AM. Effects of adiposity and PraderWilli Syndrome on postexercise heart rate recovery. J Obes 2013; (2013); 384167.

9. Tentolouris N, Liatis S, Katsilambros N. Sympathetic system activity in obesity and metabolic syndrome. Ann N Y Acad Sci 2006; (1083): 129-52.

10. Aneni E C, Nasir K. Obesity Modifies the Effect of Fitness on Heart Rate Indices during Exercise Stress Testing in Asymptomatic Individuals. Cardiology 2015; 132 (4): 242-8.

11. Kim MK, Tanaka K, Kim MJ, Matsuo T, Ajisaka R. Exercise training-induced changes in heart rate recovery in obese men with metabolic syndrome. Metab Syndr Relat Disord 2009; (7): 469-76.

12. Dimkpa U, Oji JO. Association of heart rate recovery after exercise with indices of obesity in healthy, non-obese adults. Eur J Appl Physiol 2010; (108): 695-9.

13. Barbosa Lins TC, Valente LM, Sobral Filho DC, Barbosa, Silva O. Relation between heart rate recovery after exercise testing and body mass index. Rev Port Cardiol 2015; (34): 27-33.

14. 14.Deniz F, Katircibasi MT, Pamukcu B, Binici S, Sanisoglu SY. Association of metabolic syndrome with impaired heart rate recovery and low exercise capacity in young male adults. Clin Endocrinol 2007; (66): 218-23.

15. 15.Gondoni LA, Titon AM, Nibbio F, Augello G, Caetani G, Liuzzi A. Heart rate behavior during an exercise stress test in obese patients. Nutr Metab Cardiovasc Dis 2009; (19): 170-6.

16. Han TS, Tajar A, Lean ME. Obesity and weight management in the elderly. Br Med Bull 2011; (97): 169-96.

17. Wen CP, Wai JP, Tsai MK, Yang YC, Cheng TY, Lee MC. Minimum amount of physical activity for reduced mortality and extended life expectancy: a prospective cohort study. Lancet 2011; (378): 1244-53.

18. Gallagher D, Heymsfield SB, Heo M, Jebb SA, Murgatroyd PR, Sakamoto Y. Healthy percentage body fat ranges: an approach for developing guidelines based on body mass index. Am J Clin Nutr 2000; (72): 694-701.

19. National Institutes of Health. Understanding adult obesity - National Institute of Diabetes and Digestive and Kidney Diseases. 2001; Available from: <www.niddk. nih.gov/health/nutrit/nutrit.htm> [2016 Jul 12].

20. Ainsworth BE, Haskell WL, Whitt MC. Compendium of physical activities: an update of activity codes and MET intensities. Med Sci Sports Exerc 2000; 32(9):498-504.

21. Vieira DCL, Madrid B, Pires FO, Tajra V, Farias DL, Teixeira TG. Ratings of perceived exertion in an incremental test in elderly women. Rev Bras Cineantropom Desempenho Hum 2014; (16): 106-15.

22. Cole CR, Blackstone EH, Pashkow FJ, Snader CE, Lauer MS. Heart-rate recovery immediately after exercise as a predictor of mortality. N Engl J Med 1999; (28): 1351-7. 
23. Lauer MS, Francis GS, Okin PM, Pashkow FJ, Snader CE, Marwick TH. Impaired chronotropic response to exercise stress testing as a predictor of mortality. JAMA 1999; (10): 524-9.

24. Farrell SW, Braun L, Barlow CE, Cheng YJ, Blair SN. The relation of body mass index, cardiorespiratory fitness, and all-cause mortality in women. Obes Res 2002; (10):417-423.

25. Kodama S, Saito K, Tanaka S, Maki M, Yachi Y, Asumi M, et al. Cardiorespiratory fitness as a quantitative predictor of all-cause mortality and cardiovascular events in healthy men and women: a meta-analysis. JAMA 2009; 301(19): 2024-35.

26. Imai K, Sato H, Hori M, Kusuoka H, Ozaki H, Yokoyama H, et al. Vagally mediated heart rate recovery after exercise is accelerated in athletes but blunted in patients with chronic heart failure. J Am Coll Cardiol, 1994; 24(6): 1529-35.

27. Lan, Li, Zhiwei Lian. Application of statistical power analysis-How to determine the right sample size in human health, comfort and productivity research. Build Environ 2010; 45 (5): 1202-13.

28. Christou DD, Seals DR. Decreased maximal heart rate with aging is related to reduced $\square$-adrenergic responsiveness but is largely explained by a reduction in intrinsic heart rate. J Appl Physiol 2008; (105): 24-9.

29. Seals DR, Taylor JA, Ng AV, Esler MD. Exercise and aging: autonomic control of the circulation. Med Sci Sports Exerc 1994; (26): 568-76.

30. Wei M, Kampert JB, Barlow CE. Relationship between low cardiorespiratory fitness and mortality in normal-weight, overweight, and obese men. JAMA 1999; (282):1547-53.

\section{CORRESPONDING AUTHOR}

Cristiane Rocha da Silva Departamento de Educação Física Universidade Católica de Brasília QS 7, Iote 1, Bloco G, Aguas Claras, Taguatinga

CEP: 71966-700, Brasilia (DF), Brasil

E-mail: cris.edf90@gmail.com. 